\title{
Non Destructive Testings on Damaged Multi-Cores Materials Sandwich Structures ${ }^{+}$
}

\author{
Laurent Mezeix and Komkrisd Wongtimnoi * \\ Faculty of Engineering, Burapha University, 169 Long-Hard Bangsaen Road, Chonburi 20131, Thailand; \\ laurentm@eng.buu.ac.th \\ * Correspondence: komkrisd@eng.buu.ac.th Tel.: +66-(0)-61935-4946 \\ + Presented at the Innovation Aviation \& Aerospace Industry-International Conference 2020 (IAAI 2020), \\ Chumphon, Thailand, 13-17 January 2020.
}

Published: 20 January 2020

\begin{abstract}
Sandwich structures are widely used in aeronautics both for primary and secondary structures such as landing gear doors, flaps or floors. Multi-cores materials sandwich structures presents many advantages. By adding layers with another materials that the core one, extra properties can be obtained as heat or impact protection. Manufacturing quality must be controlled and therefore bonding needs to be inspected. In this paper bonding defects between multi-layers of sandwich specimen are inspected through Non Destructive Tests. Due to its large use in industry, ultrasonic phase array is used to detect manufacturing bonding defects. Three different type of multi-cores materials specimen are investigated. Results show that due to the high PVC foam porosity, defects cannot be detected both between composite skins and foam and between foam and core material.
\end{abstract}

Keywords: composites; sandwich structures; Non Destructive Testings; phase array; defects

\section{Introduction}

Sandwich structures are used where high flexural rigidity is required, especially in the aerospace and space components. By inserting a light weight core between the two face sheets, the bending stiffness and strength are substantially increased compared with a single layer homogeneous structure, without adding much weight [1]. Typically, core consists in aramid honeycomb in aerospace applications (flaps, floor, cabin monuments) while for sport equipment (boards) where the cost is a more concern foams are used. Carbon and glass layers are mainly used as skins materials and bonding between skins and the core is usually obtained by applying an epoxy film adhesive.

Possible damage in sandwich structures can be divided into two categories: manufacturing flaws and in-service damage. Damage occurring during the life cycle such as debonding, cracking, core crushing etc., due to foreign object damage and other in service loads cannot be avoided [2]. The use of protection by adding a layers to protect the core material against damage is one technology of solving the problem of impact on composites [3]. Others properties can be also required as adding a balsa layer for heat protection [4]. In sport industry, polystyrene core material is largely use due to its low cost and easy machining but need to be protested again water and chemicals. By adding layers more bonding are required and therefore manufacturing defects can occur. Structure inspection and bonding defects detection becomes essential during the manufacturing process. Non Destructive Testing (NDT) is largely used in composite industry especially in aerospace. Different NDT methods to evaluate composites materials are available as ultrasonic, X-ray or penetrant testing [5]. However, due to the core material sandwich structures are difficult to inspect [6].

In this paper bonding defects inspection of multi-cores materials sandwich structures are investigated. Firstly, three different multi-cores materials sandwich specimen have been produced. 
Then, ultrasonic (UT) tests was performed. UT was selected due to its large use in industry. Finally, inspection results were analyzed.

\section{Materials and Methods}

To evaluate the possibility to detect manufacturing defects three different types of sandwiches have been manufactured by COBRA International and investigated. General specimen's dimensions are closed to $500 \times 500 \times 70 \mathrm{~mm}^{3}$. For each specimen's type core material was made by polystyrene (PS) foam of a thickness of $70 \mathrm{~mm}$. Type A sandwich has glass fibers as skins (Figure 1). Type B consists in PS core and PVC foam has external layer, no skins have been applied (Figure 1). Type C was made by PS core with PVC foam and glass fibers as skins (Figure 1). Glass fibers woven/PVC resin skins thickness was $0.7 \mathrm{~mm}$ while the PVC foam thickness was $4 \mathrm{~mm}$. Finally, bonding between different materials was made by PVC polymer.

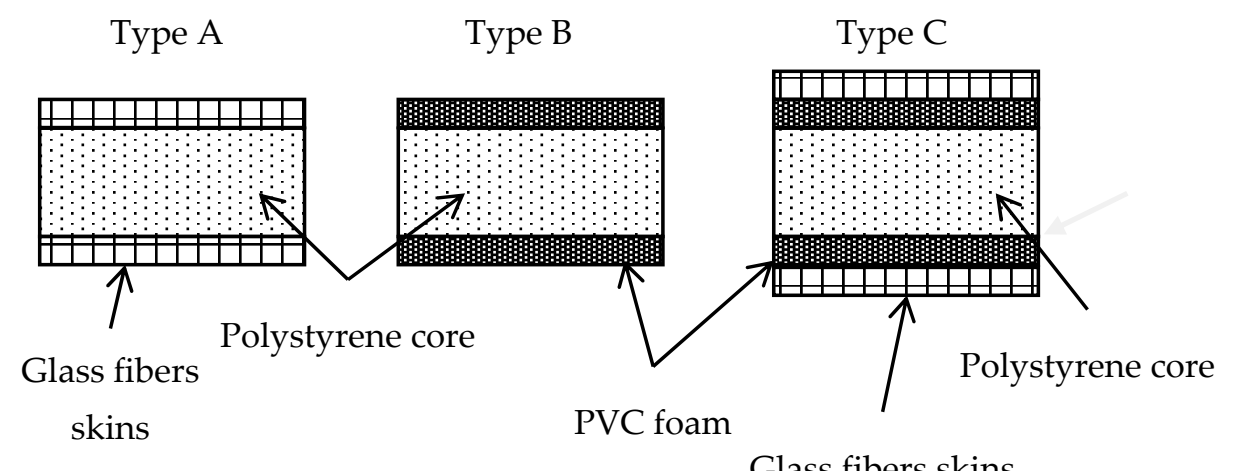

Figure 1. Cross section of the three investigated sandwich structures.

In order to detect manufacturing defects of multi-cores materials sandwich structures, Non Destructive Testing (NDT) has been performed through ultrasonic method. UT is largely used in aerospace area to control manufacturing quality and to control damage during maintenance operation [7]. NDT inspections were carried out thanks to TESTIA Smart UT 32 (Figure 2). It consists in a phased array wheel probe with 32 elements and visualization is made through a tablet. Parameters calibrations have been realized by Level 3 inspector on non-damaged specimens made with the same materials as the studied damaged specimens (Table 1).

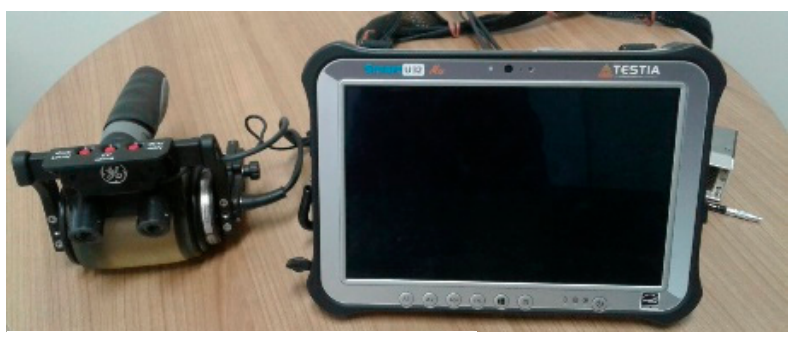

Phased array wheel probe

Tablet

Figure 2. TESTIA Smart UT 32 NDT tool inspection.

Table 1. Ultrasonic parameters used for NDT inspection.

\begin{tabular}{ccc}
\hline Parameters & Value & Unit \\
\hline Wave velocity & 3000 & $\mathrm{~m} / \mathrm{s}$ \\
Frequency & 3 & $\mathrm{MHz}$ \\
Db & 27 & 27 \\
Range & 16 & $\mathrm{~mm}$ \\
Delay & 44 & $\mathrm{~ms}$ \\
\hline
\end{tabular}




\section{Results and Discussion}

Inspection on the Type A specimen shows that phase array can detect easily bonding defect between glass fibers skins and polystyrene core (Figure 3). The same NDT method is not able to detect defects between PVC foam and polystyrene foam on the Type B specimen. No back signal can be observed on A-Scan and B-Scan (Figure 3). Indeed, due to the high porosity of the PVC foam, the ultrasonic signal is lost in the material, therefore inspection is not possible. Figure 4 shows A-Scan and B-Scan performed on Type $C$ specimen. While the front signal amplitude was amplified to 100 $\mathrm{dB}$, the back signal is too low to be detected and therefore bonding defects between glass fibers skin and PVC foam is not possible.

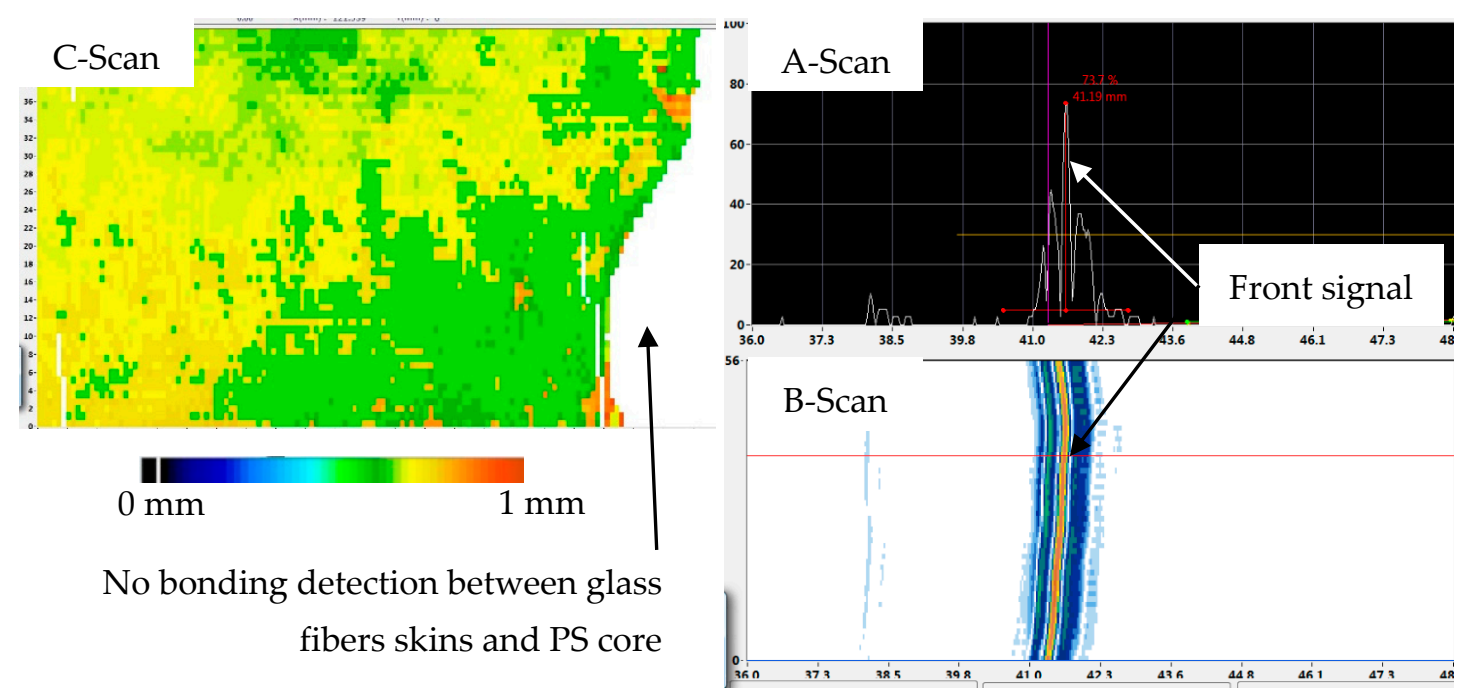

Figure 3. NDT results on Type A (C-Scan) and Type B (A-Scan and B-Scan) sandwich specimen.

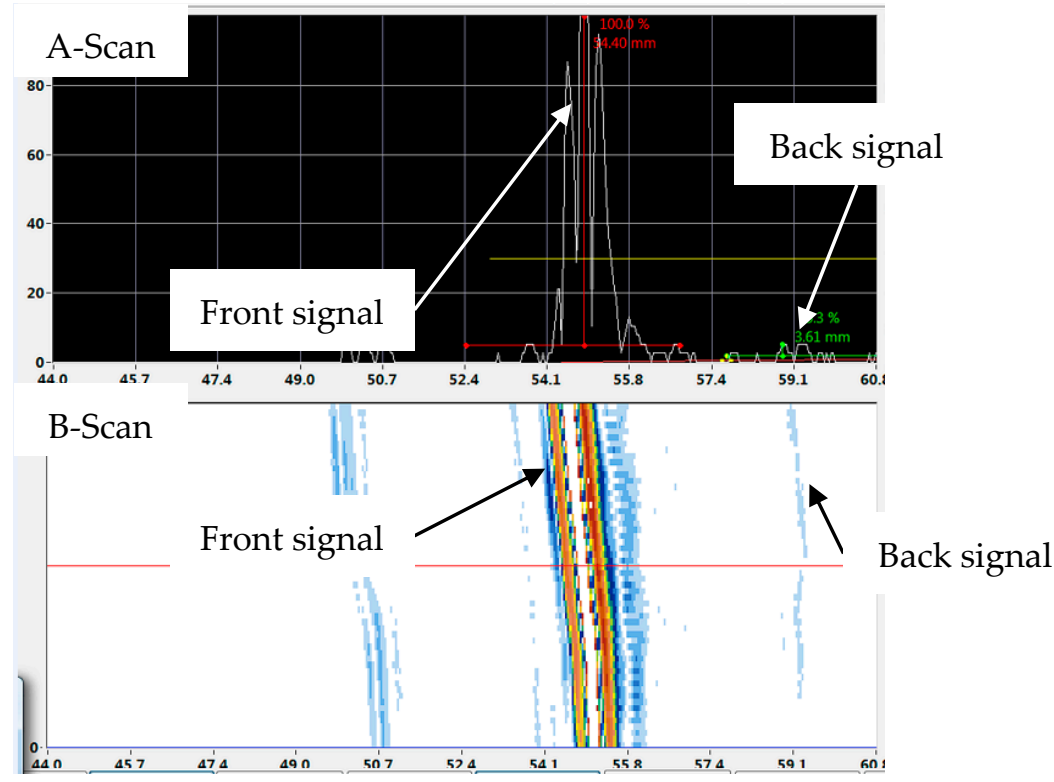

Figure 4. NDT results on Type C sandwich specimen. 


\section{Conclusions}

Non Destructive Testing have been performed on multi-cores materials sandwich specimens through phased arrays method. In order to be able to perform inspection on large structure wheel phase array has been used in this work. Three different types of sandwich specimens with $70 \mathrm{~mm}$ polystyrene as main core material have been investigated. The conclusion can be summarized as follow:

- Bonding defects between glass fibers skins and polystyrene core can be detected.

- Bonding defects between PVC foam and polystyrene core cannot be detected due to the high porosity of the PVC foam

- Bonding defects between glass fibers skins and PVC foam core can be detected but need a high skill inspector (level 3)

Ultrasonic tests show that it is not the convenient method to detect bonding defects of multicores materials sandwich. In order to be able to these type of defects work is in progress to inspected specimens trough thermography NDT.

Author Contributions: L.M. focused on investigation, on analysing of the results and writing-original draft preparation. K.W. worked on project administration, funding acquisition and writing-review, and editing. All authors have read and agreed to the published version of the manuscript.

Funding: This research was funded by Science Park Promotion Agency (SPA) of Burapha University, under Industrial Research and Technology Capacity Development (IRTC) grant number IRTC 02/2562" and "The APC was funded by The Faculty of Engineering, Burapha University".

Acknowledgments: The authors wish to thank the Geo-Informatics and Space Technology Development Agency (GISTDA) for the technical support in ensuring the progress of the research. Authors would like also to thank the company COBRA International, Thailand for the specimen manufacturing.

Conflicts of Interest: The authors declare no conflict of interest. The funders had no role in the design of the study; in the collection, analyses, or interpretation of data; in the writing of the manuscript, or in the decision to publish the results.

\section{References}

1. Raju, K.S.; Smith, B.L.; Tomblin, J.S. Impact damage resistance and tolerance of honeycomb core sandwich panels. J. Compos. Mater. 2008, 42, 385-412.

2. Abrate, S. Impact on Composite Structures; Cambridge University Press: Cambridge, UK, 1998.

3. Rahmé, P.; Bouvet, C.; Rivallant, S.; Fascio, V.; Valembois G. Experimental investigation of impact on composite laminates with protective layers. Compos. Sci. Technol. 2012, 72, 182-189.

4. Wen, X.Z.; Huang, J.; Li, Y.; Chen, P.; Jiang, L.; Long Y. Preliminary study on shielding performance of wood stuffed shield. Int. J. Imp. Eng. 2016, 91, 94-101.

5. Gholizadeh, S. A review of non-destructive testing methods of composite materials. Proc. Struct. Integr. 2016, 1, 50-57.

6. Jie, Z.; Zheng, L. Damage detection based on vibration for composite sandwich panels with truss core. Compos. Struct. 2019, 229, 117376.

7. Bossi, R.H.; Giurgiutiu, V. Nondestructive testing of damage in aerospace composites. Pol. Compos. Aerosp. Ind. 2015, 413-448. doi:10.1016/B978-0-85709-523-7.00015-3.

(C) 2020 by the authors. Licensee MDPI, Basel, Switzerland. This article is an open access article distributed under the terms and conditions of the Creative Commons Attribution (CC BY) license (http://creativecommons.org/licenses/by/4.0/). 